\title{
O COMÉRCIO DE ESCRAVOS NO BRASIL VISTO POR FUNCIONÁRIOS DIPLOMÁTICOS AMERICANOS (1845-1857) (*).
}

\author{
GEOFFREY ALAN CABAT \\ School of General Studies. Brooklyn College. \\ (New York).
}

Declarado ilegal pelo Govêrno Imperial desde 1830 , o comércio de escravos da África para as costas brasileiras foi causa de controvérsia internacional até metade do século. Os principais participantes do conflito, a Inglaterra e o Brasil, no início concordaram em tentar interromper o tráfico. Todavia, no tratado de 1826, êste acôrdo, que foi o preço britânico pelo reconhecimento da independência brasileira, estabelecia buscas e apreensão conjuntas dos navios suspeitos de traficar com o "marfim negro" (1). Porém, durante duas décadas, o govêrno brasileiro não fêz nenhuma tentativa de executar sua parte do tratado e quando o acôrdo expirou em 1845, o Império recusou-se a concordar com um nôvo pacto. Como resultado, os britânicos declararam sua intenção, pelo Ato Aberdeen de 1845 de, unilateralmente, dar buscas e julgar as tripulações escravagistas ante as côrtes do Almirantado. O período entre 1845 e 1850 , entretanto, está marcado por incursões de navios britânicos em águas territorias brasileiras e, devido à falência da cooperação mútua entre as duas nações, pelo aumento do tráfico de escravos entre a costa ocidental da Africa e o Brasil (2).

Em 1850, com o fim de impedir as incursões britânicas que aumentavam, o govêrno brasileiro decidiu agir com rigor contra os traficantes de escravos. A Lei Queiroz de 1850 tentou atingir êste objetivo declarando o tráfico escravo como pirataria e punível com a

(*). - Texto em Inglês traduzido por Maria Lúcla Carnefro (Nota da Redação).

(1). - P. A. Martin, "Slavery and Abolition in Brazil". HAHR, 1933, XLVI, p. 154.

(2). - Departamento de Estado dos Estados Unldos, Diplomatic Dispatches from the Minister to Brazil. Schenck a Webster, 17 de agôsto de 1854, $\neq$ (Doravante citado como Brazil). 
morte (3). Depois da aprovação desta lei houve um rápido declínio na atividade dos traficantes e dentro de cinco anos, à despeito de tentativas esporádicas de reativá-lo, o comércio ilícito já não era mais um problema (4) .

A posição dos Estados Unidos com respeito à proibição do comércio brasileiro era ambivalente; ainda que desde 1800 tivesse tomado forte posição contra êle, recusava-se a participar de qualquer busca conjunta ou acôrdo que tornasse efetiva a sua interdição (5). Esta recusa de participar de acordos não apenas resultava numa perda de cooperação, unida com o fim de terminar com o comércio de escravos, mas ajudava os traficantes de escravos de um modo mais direto permitindo o uso da bandeira americana como proteção para o infamante comércio.

O período que vai de 1838 a 1850 foi marcado pelo aumento do uso da bandeira americana no comércio brasileiro (6). Responsáveis antes de 1848 por uma porção mínima do tráfico, desde aí os navios que navegavam com a bandeira dos Estados Unidos, importavam ilegalmente um quinto dos negros levados ao Brasil, e apenas dois anos depois, os navios americanos transportavam ilegalmente tantos escravos quanto tôdas as outras nações combinadas (7). Com a Lei Queiroz de 1850, nôvo clima de cooperação possibilitou ao Brasil e à Grã-Bretanha juntarem fôrças de um modo mais efetivo para patrulhar a costa e os lugares suspeitos como sendo de desembarque no Brasil; cinco anos mais tarde, os Estados Unidos juntaram-se a êste esfôrço. Como resultado, em 1855 os navios americanos desapareceram virtualmente do comércio escravos no Brasil.

A cooperação dos Estados Unidos depois de 1855 deve, em grande parte, ser creditada à ação inflexível dos seus funcionários diplomáticos no Brasil de 1847 a 1860. Para o historiador, sobretu-

(3). - Martin, op. cit., p. 103.

(4). - Ibid., p. 162 .

(5). - Pelo estatuto de 1800, os cidadãos dos Estados Unidos estavam prolbidos de negociar com escravos de um país para outro. A lel de 1803 proibia a importação de escravos para os estados que tinham estatutos que proibıssem o tráfico. Pelo estatuto de 1807 fol proibida a importação de escravos para qualquer parte dos Estados Untdos. Em 1818 outro estatuto determinava prisão e multa para os que preparassem navios para o tráflco de escravos. O estatuto de 1820 tornou o tráfico de escravos pirataria. Em 1823, novo estatuto tornou a pirataria ato perpétuo. W. E. Burghardt DuBols, The Suppression of the African Slave Trade to the United States of America, (New York: Soclal Sclence Press, 1954) pp. 237-249.

(6). - W. S. Howard, American Slaves and the Federal Law, (Berkeley e Los Angeles: University of California Press, 1963) p. 20.

(7). - Ibid., p. 46. Howard baseou sua estimativa nos Registros do Almirantado Britânico e salienta que na verdade $99 \%$ dos navios americanos eram apenas nominalmente de propriedade de cidadâos americanos. 
do, a correspondência dos ministros e cônsules americanos (neste ensaio, especificamente o ministro no Rio de Janeiro e os cônsules no Rio, Bahia e Rio Grande do Sul) revelam muito sôbre os métodos de operação usados no comércio, incluindo detalhes demográficos e econômicos valiosos que de outro modo não poderiam ser aproveitados. Em suma, a correspondência diplomática depois de 1855 demonstra como a cooperação dos três poderes envolvidos com o problema do tráfico brasileiro de escravos conseguiu a morte dêsse comércio.

No fim de 1840 , ao invés de cooperarem entre si, as três nações tinham propósitos adversos, o que beneficiava os mercadores de escravos. David Tod (8), Ministro dos Estados Unidos no Brasil, de 1847 a 1851 , foi veemente em apontar que a falta de entendimento internacional estava levando a um estado de coisas deplorável. Em 1847 , salientava sua mortificação em ter que se referir à frequiência com que a bandeira dos Estados Unidos era usada no tráfico infamante (9). De acôrdo com Tod, dos 50.000 escravos importados para o Brasil em 1849, metade fôra transportada por navios americanos. Os relatórios do Ministro não apenas forneciam dados da extensão do comércio, mas também revelavam que durante a travessia, antes da chegada, os escravos eram tratados de modo brutal. São palavras de Tod:

"parte de cada carregamento morria durante a viagem e os sobreviventes eram com frequiência usados como meras bestas de carga" (10).

De fato, em um dos relatos do cônsul da Bahia, J. S. Gillmer, aparece uma carta do Chefe de Polícia desta cidade, explicando que o transporte de escravos libertos nascidos no estrangeiro para a Bahia

(8). - David Tod nasceu em Youngstown, Ohio, em 21 de fevereiro de 1805. Fol admitido para o, fôro dêsse Estado em 1827. Suas primeira posiçăo política fol a de Chefe dos Correfos de Warren, Ohfo, de 1830-1838. Foi eleito para o senado do Estado em 1838 e serviu na legislatura até 1840. Fol candidato democrático derrotado para o cargo de Governador de Ohlo em 1844 e novamente em 1846. De 1847 a 1851, Tod serviu como Ministro dos Estados Unidos no Brasil. Depois de sua volta aos Estados Unidos, retirou-se do serviço público e tornou-se um magnata do ferro e carvão na área de Youngstow. Quando servia como Presidente da "Cleveland and Mahoning Railroad", Tod, novamente envolveu-se na política. Em 1860 fol delegado de Douglas para a convenção nacional Democrática, e dois anos mais tarde fol eletto Governador de Ohio na chapa Unionista. Em 1864, depois de ser derrotado para a reelelçáo recusou a posiçño de Secretário do Tesouro oferecida pelo Presidente Lincoln. Em 1868 fol escolhido como eleitor presidencial repúblicano; morreu pouco depois da eleição do Presidente Grant. Dictionary of American Biography. (New York: Scribners e Filho, 1936)) XVIII, pp. 567-568.

(9). - Brazil, op. cit., Tod a Buchanan, 11 de outubro de $1847 \neq 11$.

(10). - Ibid. Notar a semelhança entre as estimativas de Tod e as britânicas sôbre o número de escravos transportactos pelos barcos americanos. 
era ilegal de acôrdo com a "lei de 7 de novembro de 1831". O funcionário brasileiro pedia a cooperação de Gillmer para informar aos mercadores americanos sôbre a lei em questão (11).

A correspondência diplomática não apenas contém relatos sôbre as condições do tráfico de escravos, mas também faz recomendações ao Departamento de Estado para terminar com a participação dos Estados Unidos. Tod, durante o tempo em que foi Ministro, propôs diversas medidas para conseguir tal fim (12). Acreditando que a indiferença brasileira era obstáculo soberano para a obediência rigorosa das leis anti-tráfico de escravos, o Ministro propôs um tratado entre os Estados Unidos e o Brasil que levasse os brasileiros a tomar uma posição firme contra o tráfico de escravos (13). Tod, na sua correspondência, salientava a necessidade de tal tratado, mostrando que o suposto comércio ilegal operava abertamente.

\footnotetext{
"Os negociantes de escravos" escreveu Tod, "são atrevidos e agem ostensivamente e o desembarque de escravos é com frequiência efetuado perto dos principais portos da costa" (14).
}

O comércio era tão aberto que o Ministro podia dizer que Cabo Frio, setenta e cinco milhas ao norte do Rio, era o ponto principal dos desembarques (15). Na opinião de Tod, o vergonhoso desrespeito à lei podia ser atribuido ao grande poder econômico e político dos escravagistas no Brasil e à tendência dos brasileiros de racionalizar a instituição da escravidão. Considerando os proprietários de plantafões como os principais protetores do comércio, Tod dizia com impeto,

"êles (os proprietários de escravos) florescem nos salōes da moda, sustentando equipagens esplendidas, jactando-se dos seus títulos e zombando da lei" (16).

O Ministro dos Estados Unidos acreditava que com uma mudança de atitude dos brasileiros com respeito ao tráfico êste podia ter um fim,

"a racionalização de alguns dos mais esclarecidos homens do Império é que as condições dos africanos melhoram quando êles tornam-se escravos brasileiros" (17).

(11). - Departamento de Estado dos Estados Unidos, Dispatches from the Consuls at Bahia, Gillmer a Webster, 13 de janeiro de 1851, $\neq 2$ (Doravante citado como Bahia).

(12) . - Ibid.

(13). - Brazil, op. cit., Tod a Buchanan, 11 de outubro de 1847, $\neq 11$.

(14). - Ibid., Tod a Clayton, 8 de janeiro de $1850, \neq 50$.

(15). - Ibid., Tod a Buchanan, sem data.

(16) - - Ibia., Tod a Clayton, 17 de outubro de $1845, \neq 45$.

(17). - Ibid. 
Através de pressão diplomática dos Estados Unidos, exercida por meio de um tratado, Tod esperava que o Govêrno Brasileiro tivesse que agir vigorosamente contra o tráfico de escravos e mostrar ao povo a abominação de tal comércio.

Além dos interêsses investidos, os funcionários diplomáticos americanos consideravam que obstáculo importante à supressão do tráfico eram os métodos tortuosos usados pelos comerciantes de escravos. As descrições encontradas na correspondência diplomática dão ao historiador informações inestimáveis sôbre a operação do tráfico. $\mathrm{O}$ artifício mais usado para fugir à lei era simplesmente fasificar a natuza da carga ou o destino do barco.

Robert Schenck (18), sucessor de Tod, assinalou em 1852 que diversas expedições com escravos, disfarçavam-se em expedições de gado destinadas ao Cabo da Bôa Esperança. Os mercadores de escravos supriam seus navios com quantidades de água fora do comum, farinha

"e outras mercadorias que servissem para seu frete humano",

com o pretexto de

"ter cargas de bestas brutas".

O navio então navegava para a extremidade sul da África, levando a bordo algum gado e cavalos para dar à sua atividade ilegal uma aparência de legitimidade. Então o navio dirigia-se à costa africana onde já tinha sido arranjado um encôntro para fazer o carregamento humano. Uma vez em alto mar os cavalos e o gado eram jogados ao mar e o navio negreiro dirigia-se para "um pôrto secreto não observado" na costa braseileira (19).

(18). - Robert Schenck nasceu em Franklin, Ohto, a 4 de outubro de 1809. Graduou-se na Universidade de Miaml em 1827 e permaneceu na Universidade como Instrutor até 1830 . Em 1830 começou a praticar Direito em Dayton. Em 1838 concorreu, sem sucesso, para a legislatura do Estado na chapa Whig; em 1840 fol elelto para o cargo. Entre 1841 e 1843 fol o lider legislativo de seu partido. De 1843 a 1851 schenck servlu como Representante de Ohio. Foi Ministro dos Estados Unidos para o Brasil de 1851 a 1853. $\mathrm{Em} 1860$ fol chefe Republicano apoiando Lincoln, e em 1861, com o ínícto da guerra, o ohioniano recebeu uma comissáo como General Brigadeiro. Sua carreira militar terminou quando fol ferido na Segunda Batalha de Buil Run em 30 de agósto de 1862 . No ano seguinte, Schenck fol reelelto para o Congresso e logo tornou-se um líder dos Republicanos Radicais nêsse corpo. Em 1871, Schenck serviu na Aita Comissão para estabelecer as relvindicaçбes do Alabama. Foi Ministro dos Estados Unidos na Grä-Bretanha durante curto tempo. Em 1876 retirou-se para a vida privada; desta data até sua morte, em 1890, Schenck praticou direito em Washington, D. C. Dictionary of American Biography, (New York: Scribners e Filho, 1835) XVI, pp. 427-430.

(19) . - Brazil, op. cit., Schenck a Webster, 26 de abril de 1852, $\neq 20$. 
Gorham Parks (20), cônsul dos Estados Unidos no Rio (21), já em 1850 comentou os subterfúgios usados no tráfico de escravos. Numa carta para o Ministro Tod, Parks relatou que de 1 de julho de 1846 até 1 de outubro de 1849 , oitenta e oito navios sob a bandeira americana deixaram o Rio, para mercadejar ostensivamente com tecidos, óleo de palmeira e outras modalidades, mas na realidade para dedicar-se ao tráfico de sêres humanos. Tanto Parks como Schenck sugeriram uma solução para o problema da falsificação da carga e do destino: que o comércio direto entre o Brasil e a Costa Ocidental da África em navios americanos fôsse proibido. Schenck também pediu ao Departamento de Estado para assegurar uma proibição contra a importação direta de certas mercadorias principalmente usadas no comércio de escravos: tecidos vermelhos, instrumentos musicais toscos, espingardas comuns, e pólvora (22).

O problema que preocupava principalmente os diplomatas americanos era o uso ilegal das côres americanas por estrangeiros para proteger suas atividades fora da dei. Para obter um navio americano para o tráfico de escravos, um estrangeiro precisava apenas encontrar um cidadão americano que quizesse assinar o certificado de propriedade (23). Pelo seu trabalho, o proprietário americano recebia um preço equiivalente a um terço do valor da renda do navio durante um ano (24). O americano podia então pedir ao cônsul uma carta marítima e quando o documento era concedido, o proprietário nominal podia arrendar o navio ao comerciante de escravos estrangeiro. Com frequiência o navio seguia com destino e cargas falsos. No caminho da costa da África, o navio era dirigido por capitão e tripula-

(20). - Gorham Parks nasceu em Westfield, Massachusetts a 27 de maio de 1794. Graduou-se pelo Harvard College em 1813 e foi admitido no fôro de Massachusetts em 1819. Em 1823 mudou-se para Bangor, Maine, onde continou a praticar direito. Foi eleito como Democrata para os XXIII e XXIV Congressos dos Estados Unidos em 4 de março de 1833 até 3 de março de 1837. Subsequentemente serviu como Corregedor dos Estados Unidos para - Distrito do Maine (1831-1841), e como Promotor dos Estados Unidos para o mesmo Distrito (1843-1845). Resignou êste cargo para entrar no Serviço Consular; serviu quatro anos como cónsul dos Estados Unidos no Rio de Janeiro. Em 1849 retirou-se da vida pública. Gorham Parks morreu em Bay Ridge Kings County, New York, em 1877. e fol enterrado no Greenwood Cemitery. Congresso dos Estados Unidos, Biographical Dictionary of the American Congress, (Washington, D. C.: U. S. Government Printing Office, 1950), p. 1653.

(21). - Departamento de Estado dos Estados Unidos, Dispatches from the Consuls at Rio de Janeiro, Parks a Tod, 19 de janelro de 1850, sem número. (Doravante citado como Rio de Janeiro).

(22) . - Brazil, op. cit., Schenck a Webster, 26 de abril de 1852, $\neq 24$.

(23). - Ibia., Parks a Tod, 29 de Janeiro de 1850, sem número.

(24) . - Departamento de Estado dos Estados Unidos, Dispatches from the Consuls at Rio Grande do Sul, Devine a Buchanan, 22 de dezembro de 1845 , sem número. (Doravante citado como Rio Grande do Sul). 
ção americanos. A bordo, entretanto, havia usualmente diversos "passageiros" estrangeiros (25).

Quando o navio negreiro atingia a África, a tripulação americana desembarcava e os "passageiros" tornavam-se a nova equipagem. Carregavam o navio com sua carga humana e ainda sob a proteção da bandeira americana, o navio rumava para alto mar. Ocasionalmente, à despeito das côres americanas, o navio podia ser interceptado em seu caminho por um navio de guerra inglês, inquirindo se o mesmo não estava registrado fraudulentamente (26) .

Edward Kent (27), Cônsul dos Estados Unidos no Rio de Janeiro, descreveu incidente semelhante. O barco Volusia, apreendido por um navio de guerra britânico em alto mar com escravos a bordo, ràpidamente negou sua nacionalidade americana; os mercadores de escravos consideravam que os Estados Unidos eram mais severos para com êles do que a Grã-Bretanha (28).

Muitos dos funcionários diplomáticos dos Estados Unidos no Brasil sentiam grande frustração ao conceder cartas marítimas a navios que sabiam logo mais iriam engajar-se no comércio de escravos (29).J. S. Gillmer, Cônsul dos Estados Unidos na Bahia, pretendendo usar com prudência seu direito de conceder cartas marítimas, foi alvo de grande oposição na cidade.

Penso ser necessário informar ao Departamento que em duas ocasiões (desde que o Consulado está a meu cargo) fui ameaçado com protestos, abandonos, danos, etc., por recusar conceder papéis a navios americanos condenados neste pôrto (vendidos pùblicamente para que possam demandar a costa da África). Convencido como estou, que se consentir, êstes navios partirão sob a proteção de nossa bandeira e retornarão (se não forem capturados) sob a proteção de outra ou de nenhuma bandeira, com carga de escravos (30).

(25). - O método de disfarçar os escravos é descrito em Howard, op. cit., pp. 85-91.

(26) - - Rio de Janeiro, op. cit., Kent a Clayton, 16 de agôsto de 1851. Marcado "Confidencial".

(27). - Edward Kent nasceu em Concord, New Hampshire em 1802. Foi educado em Harvard e graduado do coléglo em 1821. Estudou direito e abrlu escritório em Bangor, Maine em 1825. Fol membro do conselho escolar desta comunidade de 1829-1831, e ao mesmo tempo serviu como membro da legislatura estadual. Serviu dois periodos como Governador do Maine (1837-1838 e 1840-1841) e nos anos intermediários fol prefeito de sua cidade natal. Kent serviu seus país como mediador durante o Tratado Webster-Ashburton e como Cônsul no Rio de Janeiro de 1849 a 1853. Completou sua carreira pública servindo como Juiz da Suprema Côrte do Maine, de 1859-1873. Morreu em 1877 com a idade de 75 anos. Dictionary of American Biography,

(Scribners \& Sons) $1933 \mathrm{X}, \mathrm{pp}$. 353-354.

(28) . - Howard, op. cit., p. 20.

(29). - Lel dos Estados Unidos datada de 23 de fevereiro de 1803 exigiu que os cônsules concedessem cartas maritimas aos navios americanos logo que fôssem liberados pelas autoridades portuarias locais e tivessem pago ao cônsul e à tripulação o dinheiro que lhes deviam.

(30). - Bahia, op. cit., Gillmer a Clayton, 6 de malo de $1850, \neq 1$. 
Um dos navios referidos no comunicado de Gillmer foi o navio dos Estados Unidos, Bridgeton, suspeito de ser navio negreiro. Assim, êle escreveu a Tod, perguntando como poderia obrigar o navio a retornar aos Estados Unidos para ser registrado:

Queira Vossa Excelência informar o mais breve possível como o navio Bridgeton, recém-chegado da costa da África e prestes a seguir novamente, como fui informado, possa continuar a fazê-lo e como êste Consulado deva insistir na sua ida aos Estados Unidos para ser registrado; e em caso de recusa ser obstado de tôda ação de viagens da África a êste pôrto.

O Bridgeton foi vendido por mim, por nota de venda datada de 9 de novembro de 1849 ao Capitão Philip R. Stanhope de New York (então e agora nesta cidade). Os documentos que o habilitam a navegar foram concedidos pelo Cônsul anterior, parece-me que não posso com consciência recusar permissão para que viaje para a África sem novas instruções de Vossa Excelência para êste fim... (31).

Os funcionários americanos, não estavam investidos de poder discricionário para libertar os navios americanos o que fazia com que Gorham Parks (32) também expressasse suas suspeitas. Com referência à concessão livre de cartas marítimas, diz

"Fui obrigado em assim fazendo a ajudar mais o tráfico de escravos do que, talvez, qualquer outro cidadão dos Estados Unidos".

Mais adiante ajunta,
"cada um dos navios aos quais se concedeu cartas estão mais ou menos diretamente engajados no tráfico de escravos" (33).

O uso ilegal de cartas marítimas pelos mercadores de escravos provocou diversos apelos ao Departamento de Estado pedindo que fôsse dado aos cônsules o direito de negar os documentos aos navios suspeitos de tráfico ilícito. Infelizmente, os pedidos de reforma dos regulamentos marítimos foram ignorados (34).

Quando os navios negreiros deixavam o pôrto, os diplomatas tinham que enfrentar o problema das patrulhas navais americanas insuficientes para apreender os navios americanos envolvidos no comércio. Tod queixava-se,

"Não temos o direito de parar ou vistoriar nossos barcos nas águas tcrritoriais brasileiras e sem meios para seguir os escravagistas no mar, como poderemos diminuir o tráfico?" (35).

(31). - Ibid.

(32) . - Supra, p. 5.

(33). - Rio de Janeiro, op. cit., Parks a Clayton, 20 de julho de $1849, \neq 63$.

(34). - Brazil, op. cit. Schenck a Everett, 14 de janelro de $1853, \neq 43$.

(35). - Ibid., Tod a Clayton, 20 de janeiro de $1850, \neq 58$. 
Quando aparecia na costa um navio de guerra dos Estados Unidos, os mercadores ficavam com frequiência intimidados. Em 27 de julho de 1848, Tod relatou a James Buchanan, Secretário de Estado, a chegada do U.S.S. Allegheny,

"barco para impedir os escravagistas de operar do Rio, - enquanto êle estiver aí, os escravagistas não ousarão fazer-se ao mar" (36).

Entretanto, navios como o Allegheny eram grandes demais, incapazes de perseguir uma escuna rápida. Parks considerava que além dos navios adicionais, era necessária uma mudança na natureza do contingente naval estacionado ro Rio para que se criasse uma polícia efetivamente forte. Parks sugeriu que os pesados navios de guerra que ocasionalmente aportavam ao Rio, fôssem substituidos por um esquadrão de navios pequenos e rápidos, similares aos contingentes britânicos, que efetivamente poderiam patrulhar tôda a costa e afastar os negreiros das três milhas do limite (37).

Outra reforma sugerida pelo Ministro Schenck ao Departamento de Estado foi a liberalização das lei de evidência para justificar a tomada de um barco engajado no tráfico de escravos (38). A necessidade de reforma era crucial uma vez que as côrtes americanas tinham legislado que a única evidência incriminatória de participação no tráfico ilícito era a presença de africanos a bordo do navo suspeito (39) . Como resultado da posição tomada pelas côrtes americanas, os comandantes navais relutavam em assumir a responsabilidade da apreensão de um navio a menos que houvesse prova viva dêle ser um navio negreiro $(40)$. Schenck, entretanto, sugeria que uma evidência prima-facie fôsse suficiente para a confiscação. Pedia que:

...navios encontrados em certas latitudes entre as duas costas, tendo como parte de sua carga alguns artigos específicos, como grilhões ou algemas, pranchas finas, adeqüadas para cobrir um deck, ou uma quantidade excessiva de água ou provisões da classe das

(36). - Ibid, Tod`a Buchanan, 27 de julho de 1858, $\neq 23$.

(37). - Ibid., Parks a Tod, 29 de janeiro de 1850, sem número.

(38) . - Ibid., Schenck a Webster, 26 de abril de 1852, $\neq 24$.

(39). - Howard, op. cit., p. 88 .

(40). - Os comandantes americanos tinham recelo de confiscar qualquer navio suspeito de traficar com escravos a menos que houvesse a bordo prova viva. Dois oficiais americanos, Bishpan e Simonds, na verdade, foram julgados por detenção falsa depois de haverem forçado dols navios suspeitos a retornar aos Estados Unidos. Em decisão da côrte de justiça em 1849 , o Juiz J. Kane, absolveu os dois oficials e promulgou uma nova doutrina judicial que dava aos oficiais navais da patrulha contra os escravagistas certo grau de discernimento para deter navios em alto mar. Mas, mesmo depois desta decisão, os oficiais dos Estados Unidos hesitavam sobremaneira no exercício do seu dever. Ibid., pp. 102-110. 
usadas para alimentar e fazer subsistir uma carga de escravos, devesse ser apreendido e condenado a menos que fornecesse prova satisfatória da parte do dono ou proprietário de que estava engajado em empreendimento legal (41).

À despeito destas dificuldades, o esquadrão dos Estados Unidos conseguiu apreender diversos negreiros (42), freqüentemente com a ajuda de informações passadas aos Estados Unidos pelos agentes diplomáticos ou por cópias das dos britânicos (43).

A correspondência indica que os diplomatas americanos no Brasil, não apenas tentavam impedir os navios negreiros de fazer-se ao mar. como também, acumulavam evidências contra os organizadores americanos do comércio. Os depoimentos de testemunhas sob juramento e os documentos descritos na correspondência constituem fonte primária de material de alta qualidade para o estudo histórico do comércio. O melhor exemplo deste tipo de evidência é o testemunho de um comerciante de escravos, W. Anderson, feito a David Tod em junho de 1851 e encaminhado ao Departamento de Estado junto com $\$ 90$ enviados por Tod em 11 de junho. O Ministro dos Estados Unidos tentou fazer acusações nas côrtes contra Joshua M. Clark e Frank Smith, principais chefes do comércio brasileiro de escravos. Anderson pediu the fôsse concedido perdão e dinheiro para custear viagem de volta para fazer seu testemunho contra Clark e Smith. Tod advertiu o Secretário de Estado Webster que

Tanto Smith como Clark são homens de fortuna e têm além do dinheiro amigos influentes na pátria. Por estas razões são êles que devem ser chamados aos tribunais para responder por seus crimes. Já é tempo de ensinar uma lição aos nossos compatriotas envolvidos ou prestes a envolver-se neste tráfico inhumano e bárbaro (44).

O juramento de Anderson incluído na correspondência dizia que n navio no qual servira, devia, supostamente, partir para o Paraguai para trazer uma carga de lã, mas, ao invés, partiu para a África para dedicar-se ao tráfico de escravos. Em 4 de abril, um mês depois de sua partida do Rio, o navio chegou a São Sebastião. Nêsse pôrto, o navio foi preparado para o tráfico de escravos; foi levada madeira

(41). - Brazil, op. cit., Schenck a Webster, 26 de abril de 1852, $\neq 24$.

(42) . - Supra, N. 36.

(43). - A 4 de setembro de 1851, Schenck escreveu ao Comodoro Isaac McKeeven, da aPtrulha dos Estados Unidos contra os escravagistas, pedindo quv vigiasse um navio americano envolvido no tráfico de escravos. O Ministro dos Estados Unidos escreveu que fôra alertado a respelto do navio suspelto pelo Ministro Britanico no Rio. Brazil, op. cit., Schenck a McKeeven, 4 de setembro de $1851, \neq 244$.

(44). - Ibia., Tod a Webster, 11 de Junho de 1851, $\neq 90$. 
para um estaleiro de cargas, ferros para os escravos, feijão, água, também foi levado para bordo alimento em conserva. Assim, o navio seguiu para a África e chegou a Ambrice (45) a 4 de junho de 1849. Ao se aproximar da costa, o navio foi abordado pelo vaso de guerra Dart. Quando o navio britânico viu as côres americanas, seguiu adiante deixando um destacamento atrás de si. Quando o negreiro ancorou foi abordado por um destacamento britânico que examinou os papéis de registro americanos. O negreiro estava prestes a tomar sua carga quando verificou que o destacamento do Dart observava suas ações. Com o fim de evitar a detenção, o navio de Anderson decidiu deslocar-se até outro sítio já preparado. Finalmente, livre da vigilância britânica, êle embarcou os escravos e a 4 de julho dirigiu-se para a costa brasileira. O navio aportou a uma fazenda, quarenta milhas ao norte de Campos e desembarcou 742 escravos; quarenta tinham morrido durante a viagem. Na plantação removeram todo o equipamento adequiado ao transporte de escravos e o navio zarpou para o Espírito Santo.

Dos 742 escravos, todos tinham de um a trinta anos de idade; de 90 a 100 eram mulheres, 150 meninos e o restante rapazes e homens. Eram negociados na África a razão de $\$ 18$ por cabeça e vendidos no Brasil por $\$ 400$ cada. O lucro total da expedição variava de $\$ 12.000$ a $\$ 15.000$. Na viagem para o Brasil, afirmava Anderson, os homens eram conservados em baixo. as mulheres e as crianças podiam ficar no passadiço. Os escravos eram bem alimentados, relatava o comerciante de escravos, e muitos dêles estavam em boas condições quando o navio abordou a costa brasileira (46).

Além de Tod, outros funcionários consulares tentaram acusar os americanos envolvidos no tráfico brasileiro de escravos. Edward Kent (47) escreveu ao Secretário de Estado Clayton que um tal John Miller navegara para os Estados Unidos como passageiro do navio Thomas Watson. De acôrdo com o Cônsul, Miller estava envolvido no tráfico desde 1838. Desde esta data, Kent e seus antecessores tinham feito tremendos esforços para obter a prisão e rendição de Miller. Entretanto, desde que não havia nenhum tratado de extradição entre os Estados Unidos e o Brasil, pouco podia ser feito contra o traficante de escravos. Tendo em vista que Miller fizera inúmeras viagens durante os anos de 1848 e 1850 , Kent sugeria que o govêrno dos Estados Unidos tentasse colher informações para fazer uma acusação contra êle (48). Kent diz:

(45) . - O local mencionado é provàvelmente o pôto de Ambris no Rio Loge, em Angola

(46). - Brazil, op. cit., Tod a Webster, 11 de funho de $1851, \neq 90$.

(47) . - Supra, p. 6.

(48). - Rio de Janeiro, op. cit., Kent a Clayton, 27 de dezembro de $1850, \neq 118$. 
Não tenho nenhuma prova direta sôbre o assunto, mas êle (Miller) é olhado por todos em geral como o mais conhecido dos envolvidos no tráfico infamante (49).

As atividades investigatórias do corpo diplomático dos Estados Unidos no Brasil não foram o fator que eventualmente terminou com o comércio brasileiro de escravos, a principal razão para isto foi a determinação renovada por parte do govêrno brasileiro, expressa na Lei Queiroz de 1850. Tod não estava otimista com referência à duração dos efeitos da lei; acreditava que seria seguida enèrgicamente durante poucos anos e depois esquecida.

"Até que haja uma mudança decidida nos sentimentos anti-escravagistas, temo que a lei se torne palavra morta" (50).

O sucessor de Tod, Robert Schenck, tinha opinião igualmente pessimista com respeito à duração da eficácia da Lei Queiroz. Acreditava que a Câmara dos Deputados estorvaria a execução rigorosa da nova legislação porque
"muitos senadores e deputados eram plantadores de café e açú- car e opunham-se devido aos seus priconceitos, e como também su- punham pelos seus interêsses, à extinção do tráfico" (51).

Mesmo assim, Schenck tinha alguma esperança na supressão do tráfico de escravos porque considerava que

"a lei de 4 de setembro de 1850 fôra redigida para ser atuante se seguida fielmente e com rigor" (52).

Pouco mais de um ano depois da aprovação da Lei Queiroz. Schenck escrevia a Webster que

Como conviç̧ão resultante de observação chegada como também das respostas a êstes inquéritos, no que concerne ao tráfico de escravos, no presente momento, parece que as autoridades governamentais manifestam o propósito, em alguns casos executado com bom grau de eficiência, de por um fim às futuras importações de negros da África. Até que ponto êstes esforços serão relaxados e a vigilância adormecida, e quando será removida a pressão das circunstâncias existentes, é caso para ser visto no futuro (53).

Schenck, do mesmo modo como estava desejoso de ver o tráfico eliminado, opunha-se a que fôssem infrigidos os direitos de propriedade dos Estados Unidos por patrulhas de navios estrangeiros. No

\footnotetext{
(49). - Ibid.

(50). - Brazil, op. cit., Tod a Webster, 17 de Janeito de $1850, \neq 64$.

(51) . - Ibid., Schenck a Webster, 4 de maio de 1851 , sem número.

(52). - Ibia.

(53). - Ibia., Schenck a Webster, 29 de novembro de 1851, $\neq 10$.
} 
caso Herold, por exemplo, o ministro americano defendia os direitos dos cidadãos americanos na tentativa de reapossar-se de um navio, originalmente dêles, que fôra confiscado pelo govêrno brasileiro, como participante do tráfico de escravos. Schenck temia que houvesse uma reativação do tráfico e escrevia a Webster:

Este tráfico infame e desumano, graças, devo dizer à vigilância dos cruzadores britânicos e à disposição manifesta e às medidas tomadas pelo Ministro de Estado compondo a administração agora no poder, neste govêrno, parecia por um período de um ano ou mais, estar próximo senão completamente supresso e findo. Mas há muitas indicações de seu reativamento, e sinto ter de informar que nas condições presentes, nenhuma bandeira está em condições melhores para ser prostituida no mau uso de proteger os que estão engajados neste negócio que a nossa (54).

Na opinião do Ministro, a alta do custo dos escravos era a principal razão para antecipar a reativação do comércio:

"devido às dificuldades para a importação de novos suprimentos de escravos, o preço dêles dobrou ùltimamente no mercado e um simples carregamento desembarcado com sucesso, depois de vendido faria a fortuna dos aventureiros" (55).

Com referência à participação dos navios dos Estados Unidos na reabertura do tráfico de escravos. Schenck mencionava que dois vasos tinham recentemente zarpado para a costa da África e sua carga indicava que sua missão real era o transporte de negros para o Brasil. Por volta de 1852 , Schenck tornou-se muito aborrecido com a indiferença do Departamento de Estado para com os seus relatórios sôbre a recente partida de navios dos Estados Unidos para a costa da África. Salientava,

"se houvesse um vaso de gurrra no pôrto, êles (os traficantes de escraves) poderiam ser seguidos e observados, no entanto, isto não traria nenhuma prova para detê-los, de acôrdo com as leis existentes e sua condenação pelas côrtes da pátria" (56).

Schenck relata que por ordem do Ministro da Justiça brasileiro, um vaso americano foi vistoriado $\mathrm{e}$

"sua carga e mercadorias adotadas no tráfico de escravos africanos, talvez, tivesse levado à sua detenção se fôsse um navio inglês ou brasileiro, de acôrdo com a convenção existente entre as duas nações" (57).

(54). - Ibid., Schenck a We3bster, 26 de abril de 1852, $\neq 241$.

(55). - Ibid.

(56). - Ibid.

(57). - Ibid. 
Uma vez que o navio era americano, pôde navegar para a costa africana .

No princípio de 1853, Schenck escreveu ao Secretário de Estado, Edward Everett, que havia sido indicado para o cargo há pouco tempo, pedindo navios menores e mais rápidos para suprimir o ressurgimento do tráfico de escravos

"que se verificou recentemente sob as circunstâncias precisas para as quais tinha já chamado a atenção" (58). Continuava, ... não quero ser interpretado como queixando-me da negligência anterior do nosso Departamento, mas com facilidade compreendereis como é desencorajante para um agente diplomático no exterior verificar que por mais vigilante que tenha sido, falhou em persuadir as autoridades com as quais correspondeu-se na pátria de que havia interêsse nas informações que comunicava, ou que seus pedidos repetidos de conselhos ou instruções não valiam qualquer consideração ou resposta (59).

Os temores de Schenck sôbre as atividades dos dois navios americanos que haviam deixado o Rio (60) foram confirmados em fevereiro de 1853. Nessa data, o brigue Camargo chegou novamente ao Brasil com umas poucas centenas de negros a bordo (61). O navio chegara antes ao Rio vindo da Califórnia em $1851 \mathrm{com}$ uma carga de peles e lá permanecera por curto tempo; zarpou, então, para Moçambique e Madagascar (62) onde embarcou 200 escravos chegando a

Baracuhy, um pequeno pôrto não freqüentado a poucas léguas da cidade para evitar as buscas e a detenção. O navio foi então incendiado e o casco partido e afundado. Seu capitão, Nathaniel Gordon (63) e a tripulação, fugiram através do país. Os negros precipitaram-se para as montanhas. Cêrca de 50 foram encontrados e estão a cuidado das autoridades brasileiras. Quatro marinheiros foram presos, e estão agora na prisão aguardando julgamento. Assim também, W. George Marsden, cidadão dos Estados Unidos, residente nesta cidade, que era o consignatário do Camargo quando estava aqui em abril. O Capitão Gordon conseguiu iludir a perseguição e escapou, ao que se pensa, para Montevidéo de onde provàvelmente foi para os Estados Unidos (64).

(58). - Supra, p. 11.

(59). - Brazil, op. cit., Schenck a Everett, 14 de Janeiro de $1853, \neq 43$.

(60). - Supra, p. 12.

(61). - Brazil, op. cit., Schenck a Everett, 5 de fevereiro de $1853, \neq 45$.

(62). - Năo era comum os mercadores de escravos brasileiros obterem sua carga na costa leste da Africa. Howard, op. cit., p. 6.

(63). - Nathanael Gordon foi o único americano executado por participaça no tráfico de escravos. Foi indiciado pela Lei de 1800 no fim do veráo de 1860. Gordon foi condenado em novembro de 1861 e executado em fevereiro de 1862. Howard, op. cit., pp. 201-202.

(64). - Brazil, op. cit., Schenck a Everett, 5 de fevereiro de $1853, \neq 45$. 
Schenck prometeu ao Secretário de Estado Everett tentar assegurar provas contra o Capitão Gordon e sua tripulação e fazer dêles exemplo para outros cidadãos dos Estados Unidos que estavam engajados no comércio, pois

\footnotetext{
"temo", escreveu Schenck, "a menos que alguma medida mais efetiva seja tomada pelo Congresso e pelo Executivo, devemos esperar ver, logo e freqüentemente repetidas, as circunstâncias de crime sob a proteção da bandeira dos Estados Unidos" (65).
}

Como foi relatado no comunicado de Schenck (66), um negociante residente no Rio, George Marsden, foi preso como agente do Camargo. Fernando Coxe, Encarregado dos Negócios dos Estados Unidos no Rio conseguiu a libertação do negociante depois dêste ter estado encarcerado por quatro meses sem ter sido julgado (67). Logo depois de solto, foi novamente preso e deportado.

Explicando a atitude de seu govêrno, o Ministro da Justiça brasileiro declarou que desde a primeira detenção de Marsden, acumularam-se mais provas contra êle. Um dos documentos descobertos, um contrato de escravos entre Marsden e um tal Francisco Riverosa, foi encaminhado a $\mathrm{Mr}$. Coxe (68). O contrato estipulava que Marsden deveria entregar na costa africana, em lugar designado por Riverosa, o navio americano Volusia (69) pela soma de 15 contos de réis. Riverosa devia pagar tôdas as despesas neçessárias para preparar o barco para a viagem. Tôdas as despesas de navegação e tripulação deveriam ser pagas por Marsden. O contrato é valioso històricamente por mostrar que grande soma era ganha pelos capitães de mar americanos pelo aluguel de seus barcos aos traficantes de escravos brasileiros $(70)$.

Durante vários anos depois do incidente do Camargo, houve uma queda marcada na importação de africanos para o Brasil (71). Como resultado, o assunto comércio de escravos é raramente mencionado nos despachos diplomáticos dos funcionários americanos entre 1853 e 1855 . Ainda assim, neste último ano, o assunto do tráfico de escravos foi revivido com a captura de um navio dos Estados Unidos, o Mary E. Smith. Em dezembro de 1855, o Ministro dos Estados

\footnotetext{
(65). - Ibia.

(66). - Ibid.

(67). - Ibia., Coxe a Marcy, 2 de julho de 1853, $\neq 65$.

(68) . - Ibid., Ministro do Exterior do Brasil a Coxe, 1 de julho de $1853, \neq 650$.

(69). - Supra, p. 6.

(70). - Brazil, op. cit., Minlstro do Exterior do Brasil a Coxe, 1 de Julho de 1853, $\neq 65 \mathrm{H}$.

(71) . Martin, op. cit., p. 161
} 
Unidos no Rio, William Trousảale (72), recebeu informações do Encarregado de Negócios britânico, Mr. Ferningham, que um navio . americano de 122 toneladas, o Mary E. Smith, deixara Boston (73) e suspeitava-se de estar envolvido no tráfico de escravos. Depois do recebimento da informação, Trousdale ordenou ao Comandante Satter, oficial da patrulha contra os escravagistas, da Marinha dos Estados Unidos, que vigiasse o navio suspeito (74). O Mary E. Smith apareceu e foi capturado com 370 escravos a bordo em janeiro de 1856 pelo navio de guerra brasileiro Olinda (75) .

A captura do navio causou grande indignação no Brasil, pois descobriu-se que as condições a bordo eram tão ruins que 106 negros morreram durante a viagem e os que sobreviveram estavam em condições físicas muito precárias. A indignação de Gillmer estava evidente quando escreveu:

"Este negócio apresenta a pior forma de todos os que estiveram sob minha observação; ainda é mais grave que um aventureiro estrangeiro (Capitão Cratonick do Mary E. Smith) acobertado pelo manto da cidadania americana tivesse 0 poder de assim desgraçar nossa nação" (76).

Tanto Gillmer como Trousdale recusaram-se a ajudar o capitão americano e a tripulação do Mary E. Smith (77). O Ministro, em nota a Gillmer, lembrava ao Cônsul

"êste é um caso de culpa bem definida pelo ato do Congresso de Quinze de Maio de 1820 (78) constituindo-se o comércio africano de escravos como pirataria e punível com a morte" (79).

(72). - William Trousdale nasceu em Orance County, North Carolina, em 13 de setembro de 1790. Quando tinha seis anos, sua familia mudou-se para o Tennessee. Lutou na milicia na Guerra Grega de 1813 e serviu sob as cordens do General Jackson na Batalha de New Orleans. Em 1835 fol o candidato democrata vitorioso para o senado do Estado, e fol recompensado pelo seu partido cinco anos depois, sendo chamado como eleitor para a chapa Van Buren. Trousdale lutou com distinçăo na Guerra Mexicana, tendo tomado parte na ação de Churubusco, Molino del Rey e Chapaultepec. Em 1849, foi eleito Governador do Tennessee. Três anos depois, quando seu prazo de govêrno terminou, Trousdale fol nomeado Ministro dos Estados Unidos no Brasil, posiçăo que desempenhou durante cinco anos, aposentando-se finalmente em 1857. Trousdale viveu como cidadáo particular o resto de sua vida; morreu em 1872 em Nashville, Tennessee, em 27 de março. National Encyclopedia of American Biography, (New York: James J. White e Companhia, 1897) vIr, p. 209.

(73). - Os oftciais do pỏrto de Boston tinham informaçóes a respelto da missăo a que se propunha o Mary E. Smith; entretanto, tentativas para prender seu Capitão, Vincent Cratenick, e deter o navio em Boston foram em vão. Howard, op. cit., pp. 124-126.

(74). - Brazil, op. cit., Trousdale a Marcy, 4 de dezembro de $1855, \neq 45$.

(75) . - Ibid., Trousdale a Marcy, 13 de feveretro de 1856, $\neq 48$.

(76) . - Bahia, op. cit., Gillmer a Marcy, 2 de fevereiro de $1856, \neq 65$.

(77). - Ibia.

(78). - Brazil, op. cit., Trousdale a Gillmer, 5 de fevereiro de 1856, $\neq 48 \mathrm{C}$.

(79). - Ioia. 
Gillmer, depois de examinar os documentos do navio, informou ao Departamento de Estado que muitos indivíduos e companhias nos Estados Unidos estavam envolvidos na expedição do Mary E. Smith. Um dêles era o já mencionado John Miller, mestre de navios de Baltimore que estava envolvido no tráfico por muitos anos (80). O Cônsul na Bahia, pedia, também, ao Departamento de Estado, para investigar a Companhia dos Irmãos Finganiere de New York, da qual um dos sócios era Manuel Basílio da Cunha Reis (81), que parecia ser o principal planejador da expedição (82) . Reis foi colocado sob custódia e indiciado na Lei de 1818 que colocava fora da lei a preparação de navios

\section{"com a intenção de empregá-Irss no comércio, o que lhes pro- porcionaria a prisão" (83).}

Trousdale, pediu, para o advogado dos Estados Unidos em Boston (84), o empréstimo para a Côrte Distrital em Massachusetts, dos documentos apresados no Mary E. Smith para serem usados no julgamento (85). Reis, infelizmente, nunca foi julgado nos Estados Unidos, devido a detalhes legais. Ainda assim, o incidente do Mary $E$. Smith demonstrou que as três nações trabalhando em conjunto podiam, com eficiência, por um paradeiro ao tráfico (86). A cooperação entre os govêrnos britânico e americano é especialmente relevante, uma vez que as duas nações estavam próximas da guerra devido à disputa de fronteiras no Oregon e no Maine (87).

O valor dos relatórios diplomáticos, não editados, é pouco reconhecido pelos historiadores americanos que abordam o tráfico de escravos. L. F. Hill, por exemplo, não utiliza êsses relatórios no seu trabalho sôbre as relações diplomáticas entre os Estados Unidos e o Brasil (88). Warren S. Howard, também, não faz uso dêstes relatórios em seu American Slavers and the Federal Law (Escravagistas americanos e a Lei Federal) (89). Talvez êsses documentos permaneçam no esquecimento devido ao fato de muitos historiadores apoia-

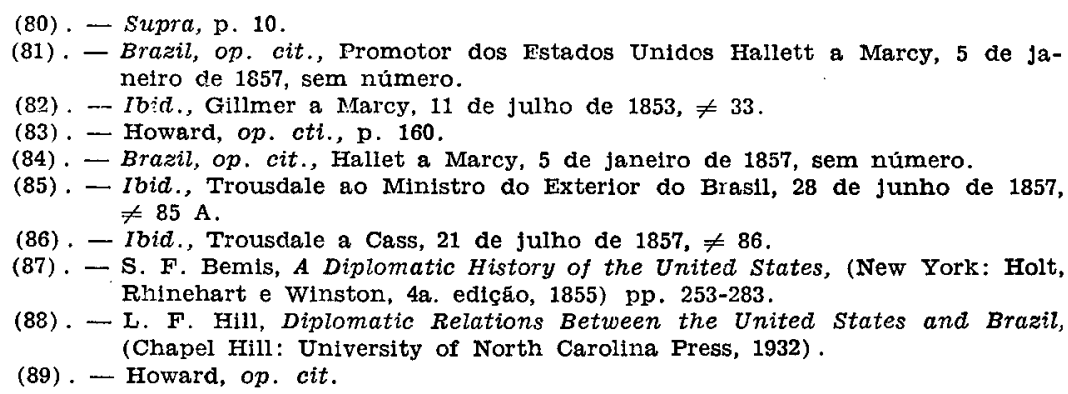


rem-se excessivamente na edição de Manning (90) dos despachos diplomáticos nos quais quase tôdas as referências à escravidão e outros tópicos de importância social são negligenciados. O fracasso dos historiadores em não considerar êstes despachos històricamente importantes é deplorável, porque os embaixadores e cônsules deviam, por dever do cargo que ocupavam, narrar o mais objetivamente possível os acontecimentos quando ocorressem. Quando, por exemplo, Tod relata que o temor de incursões britânicas em águas territoriais brasileiras, foi o principal fator para a aprovação da Lei Queiroz, devemos dar grande crédito à sua observação. Além de nos dar uma análise concisa da política contemporânea, êstes despachos incluem documentos de primeira ordem para o estudo do tráfico de escravos que são de grande valor, especialmente tendo-se em vista o fato de que muitos volumes do material sôbre êste tópico foram destruídos no incêndio da residência de Ruy Barbosa.

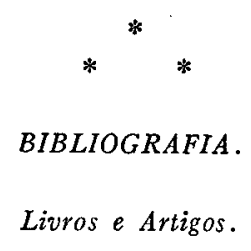

Colegeras (José). - History of Brazil, Chapel Hill. University of North Carolina Press, 1939.

DuBois (W. E. B.). - The Suppression of the African Slave Trade to the United States of America. The Social Science Press, 1954.

Graham (R.). - "Causes for the Abolition of Negro Slavery in Brazil", in. The Hispanic American Historical Review. Vol. XLVI, Maio 1966.

Haring (C.). - Empire in Brazil. Cambridge, Mass. The Harvard University Press, 1958.

Hill (L. F.). - Diplomatic Relations Between the United States and Brazil. Durham, Duke University Press, 1932 (não utiliza originais diplomáticos inéditos e despachos consulares).

Howard (W. S.). - American Slavers and the Federal Law. Berkeley and Los Angeles. University of California Press, 1932. (não utiliza originais diplomáticos inéditos e despachos consulares).

Martin (P. S.). - "Slavery and Abolition in Brazil", in The Hispanic American Historical Review, 1933, pp. 151-193.

Mathieson (W. L.). - Great Britain and the Slave Trade. 1839-1865, London, Longmans Green \& Co., 1929.

(90) . - W. R. Manning, Diplomatic Correspondence of the United States, Inter-American Affairs, 1831-1860, (Wash1ngton, D. C.: Carnegle Fndowment for Peace, 1932-1939, 12 vols.). 
Rodrigues (F. W.). - África e Brasil, Rio de Janeiro, Editôra Civilização Brasileira, 1961.

\section{Fantes Bibliográficas.}

Dictionary of American Biography, N. Y. Scribners \& Sons, 1935-1936, Vols. XVI \& XVIII.

National Encyclopedia of American Biography, N. Y., James T. White \& Co., 1897 Vol. VII.

U. S. Congress, Biographical Dictionary of the American Congress (Washington D. C.: Government Printing Office) 1950.

Documentos públicos.

Arquivos Nacionais (Washington D. C.).

Departamento de Estado dos Estados Unidos da América, Diplomatic Dispatches of U.S. Ministers from Brazil to the Departament of State. 1847-1860.

Departamento de Estado dos Estados Unidos da América, Consular Dispatches of $U$. S. Consuls at Bahia to the Departament of State, 1847-1860.

Departamento de Estado dos Estados Unidos da América, Consular Dispatches of $U$. S. Consuls at Rio de Janeiro to the Departament of State, 1847-1857.

Departamento de Estado des Estados Unidos da América, Consular Dispatches of $L^{T}$. S. at Rio Grande do Sul to the Departament of State, 1845-1860. 